\title{
Assessment of the breath alcohol concentration in emergency care patients with different level of consciousness
}

\author{
Annika Kaisdotter Andersson ', Josefine Kron ${ }^{2,3}$, Maaret Castren ${ }^{2,3}$, Asa Muntlin Athlin ${ }^{4,5,6,7^{*}}$, Bertil Hok \\ and Lars Wiklund ${ }^{8}$
}

\begin{abstract}
Background: Many patients seeking emergency care are under the influence of alcohol, which in many cases implies a differential diagnostic problem. For this reason early objective alcohol screening is of importance not to falsely assign the medical condition to intake of alcohol and thus secure a correct medical assessment.

Objective: At two emergency departments, demonstrate the feasibility of accurate breath alcohol testing in emergency patients with different levels of cooperation.

Method: Assessment of the correlation and ratio between the venous blood alcohol concentration (BAC) and the breath alcohol concentration (BrAC) measured in adult emergency care patients. The BrAC was measured with a breathalyzer prototype based on infrared spectroscopy, which uses the partial pressure of carbon dioxide $\left(\mathrm{pCO}_{2}\right)$ in the exhaled air as a quality indicator.
\end{abstract}

Result: Eighty-eight patients enrolled (mean 45 years, 53 men, 35 women) performed 201 breath tests in total. For $51 \%$ of the patients intoxication from alcohol or tablets was considered to be the main reason for seeking medical care. Twenty-seven percent of the patients were found to have a BAC of $<0.04 \mathrm{mg} / \mathrm{g}$. With use of a common conversion factor of 2100:1 between BAC and BrAC an increased agreement with BAC was found when the level of $\mathrm{pCO}_{2}$ was used to estimate the end-expiratory $\mathrm{BrAC}$ (underestimation of $6 \%, r=0.94$ ), as compared to the $\mathrm{BrAC}$ measured in the expired breath (underestimation of $26 \%, r=0.94)$. Performance of a forced or a non-forced expiration was not found to have a significant effect $(p=0.09)$ on the bias between the BAC and the BrAC estimated with use of the level of $\mathrm{CO}_{2}$. A variation corresponding to a $\mathrm{BAC}$ of $0.3 \mathrm{mg} / \mathrm{g}$ was found between two sequential breath tests, which is not considered to be of clinical significance.

Conclusion: With use of the expired $\mathrm{pCO}_{2}$ as a quality marker the $\mathrm{BrAC}$ can be reliably assessed in emergency care patients regardless of their cooperation, and type and length of the expiration.

Keywords: Blood alcohol concentration, Breath alcohol concentration, Patient cooperation, Emergency care patients

\section{Introduction}

Many patients seeking care at the hospital emergency departments (EDs) are under the influence of alcohol, which in many cases implies a differential diagnostic problem [1-3], and assessing the influence from alcohol based on patient anamnesis, clinical signs or characteristics introduce inaccuracies $[4,5]$. For this reasons early

\footnotetext{
* Correspondence: asa.muntlinathlin@adelaide.edu.au

${ }^{4}$ Department of Medical Sciences, Uppsala University, Uppsala, Sweden

${ }^{5}$ School of Nursing, University of Adelaide, Adelaide, Australia

Full list of author information is available at the end of the article
}

objective alcohol screening is of importance in order not to falsely assign the medical condition to intake of alcohol and thus secure a correct medical assessment $[1,3,6,7]$.

A breathalyzer provides a non-invasive and rapid quantification of the patients' breath alcohol concentration (BrAC). With use of a conversion factor, called the blood:breath ratio (BBR), the blood alcohol concentration (BAC) can be estimated [8,9]. However, the accuracy of the measured $\mathrm{BrAC}$ and thus the estimate of the BAC depend on the duration of the expiration which requires cooperation and good respiratory ability from the

\section{Biomed Central}


person tested [10]. In Sweden most EDs are equipped with breathalyzers but the usability of these devices are limited by the requirement of the patient's cooperation. For this reason invasive, costly, and time-consuming blood analysis is still widely used.

The objective of this study is to evaluate a breathalyzer prototype which uses expired partial pressure of $\mathrm{CO}_{2}$ $\left(\mathrm{pCO}_{2}\right)$ as a quality marker of the breath test. Our hypothesis is that through simultaneous measurement of expired alcohol and the $\mathrm{pCO}_{2}$, the $\mathrm{BrAC}$ can be reliably assessed regardless of patient cooperation and respiratory ability. The hypothesis is evaluated through comparison of the estimated $\mathrm{BrAC}$ and the measured venous BAC.

\section{Materials and methods \\ The study design \\ Study settings and patients}

The study was undertaken between November 2010 and June 2011 at two of the largest emergency departments (EDs) in Sweden; Uppsala University Hospital, a level 1 trauma center with approximately 53000 annual visits, and Södersjukhuset in Stockholm a hospital with nearly 90000 annual visits. A small number of enrolled nurses working at each ED were assigned to identify and recruit patients over the age of 18 for whom determination of the influence of alcohol would be of clinical benefit, for example patients believed to be sober and patients with variable consciousness.

For each included patient a study protocol was filled in with data regarding age, gender, estimated weight and height, level of consciousness, chief complaint, suspicion and history of alcohol consumption and drug usage. The time for blood alcohol and breath alcohol samplings, and the result of the two analyses were documented. Informed consent was collected in advance from subjects whom were able to be informed or afterwards for the subjects highly under the influence and/or with variable consciousness, at the time of admittance. Data collection from these two EDs was approved by the Regional Ethical Review Board in Uppsala (registration no 2010/048 and 2010/308).

A required study population was predicated from a calculation of the confidence interval (CI) for different samples sizes. At approximately 45 subjects the curve starts to level off and the benefit from including more subjects was therefore minimal. The calculation was based on an assumed bias of $0.068 \mathrm{mg} / \mathrm{g}$ and a standard deviation (SD) for difference of $0.0452 \mathrm{mg} / \mathrm{g}$ according to a study comparing the BrAC with the BAC [9]. The aim was to recruit 45 patients from each of the two EDs.

\section{Measurement and procedure}

Measurement of the blood alcohol concentration

At both EDs standard routine involves blood analysis for toxic substances in patients for whom a suspicion of intake of alcohol or other substances exists. Blood sampling and the serum ethanol analysis were performed according to standard procedure and analyzed with gas chromatography at the clinical chemistry department at Södersjukhuset in Stockholm, and with immunoassay analyzer at Uppsala University Hospital.

\section{Measurement of the breath alcohol concentration}

The enrolled nurses were trained to perform breath testing with a handheld breathalyzer prototype with dimensions of $150 \times 85 \times 50 \mathrm{~mm}$, and a weight of less than $200 \mathrm{~g}$. The breath test was initiated by the user from a touch screen PC connected to the breathalyzer, which also presented the result. The breathalyzer utilizes infrared (IR) transmission spectroscopy [11], a highly reliable technique utilized by evidential breathalyzers [12,13]. IR spectroscopy enables continuous and simultaneous measurements of both the expired alcohol and the partial pressure of $\mathrm{CO}_{2}$. To ensure low sensitivity to other substances occurring in normal breath a wavelength of $9.5 \mu \mathrm{m}$ was used for detection of ethanol, whereas a wavelength of $4.3 \mu \mathrm{m}$ was used for $\mathrm{CO}_{2}$.

The breathalyzer continuously sampled 13 seconds of normal breathing through the patient's mouth and nose, with use of a disposable breathing mask (Ecomask II, size 2, Intersurgical Ltd., U.K), equipped with a bacterial filter (Electrostatic Filter Media MES, Munktell Filter $\mathrm{AB}$, Sweden). The rationale of using $\mathrm{CO}_{2}$ for enabling BrAC determination in passive shallow expiration has been subject to previous investigation [14-16]. For estimation of the end-expiratory BrAC (BrACest) the breathalyzer tested uses equation (1) with the assumption that the $\mathrm{pCO}_{2}$ in alveolar air is $4.8 \mathrm{kPa}$ with a standard deviation of $10 \%$ [17]. From studies of expirograms of $\mathrm{CO}_{2}$ recorded from healthy persons and patients with COPD [14-16] a breath sample with a measured $\mathrm{pCO}_{2}$ over $1.5 \mathrm{kPa}$ was considered approved. A breath sample with a measured $\mathrm{pCO}_{2}$ over $4.8 \mathrm{kPa}$ was considered as a complete expiration and the measured $\mathrm{BrAC}$ was considered to be valid as the end-expiratory BrAC. The measurement accuracy of the breathalyzer prototype was $\pm 0.05 \mathrm{mg} / \mathrm{l}$ or $\pm 10 \%$ of the measured breath alcohol value.

At least two breath tests were performed with each subject. Whether the subject was awake or sleeping/had a lower level of consciousness, and performed a forced or a non-forced expiration was documented. Since the patients were not regarded to have consumed alcohol less than 15 minutes prior to breath testing, no attempt to remove any influence of mouth alcohol was done before testing.

$$
\frac{B r A C_{\text {est }}}{B r A C_{\text {meas }}}=\frac{p C O 2_{\text {end-exp }}}{p C O 2_{\text {meas }}}
$$

$B r A C_{e s t}=$ the breath alcohol concentration estimated to be valid after a forced expiration. 
$B r A C_{\text {meas }}=$ the breath alcohol concentration measured in the breath sample.

$p C O 2_{\text {end-exp }}=$ the assumed partial pressure of carbon dioxide after a prolonged, end-expiratory, expiration.

$p C O 2_{\text {meas }}=$ the measured partial pressure of carbon dioxide measured in the breath sample.

\section{Data analysis}

The serum ethanol concentration values from the analysis were transformed from $\mathrm{mmol} / \mathrm{l}$ to $\mathrm{mg} / \mathrm{g}$ in whole blood, which corresponds to parts per thousand, using the conversion factor recommended for scientific use; 0.0376 [18]. The conversion factor used does not account for any safety margin applied for legal use. Regression analysis and calculation of the Pearson correlation coefficient and the residual standard deviation have been performed. In addition, Bland-Altman analysis [19] and calculation of the mean, upper and lower limits of agreement (LOA) was performed. The LOAs corresponds to a range in which $95 \%$ of the differences between two separate measurements of two specimens or tests would be found. For comparison between the blood and breath specimens a blood:breath ratio (BBR) of 2100:1 was used. With consideration to the density of whole blood, a BBR of 2100:1 results in a ratio of 2:1 between the BAC $(\mathrm{mg} / \mathrm{g})$ and $\mathrm{BrAC}$, which therefore can be presented as $\mathrm{mg} / 2 \mathrm{l}$ breath $[9,18]$. The ratio of 2:1 was used for the identity line in the regression analysis plots, and the expression of $\mathrm{BrAC}$ in the unit of $\mathrm{mg} / 2 \mathrm{l}$ in the Bland-Altman plots. In addition the BBR for each pair of blood and breath tests was also calculated.

Analyses of one set of paired data per test subject; the blood sample and the first approved breath test $(\mathrm{n}=88)$, and all approved breath tests $(\mathrm{n}=201)$ have been performed. Independent $\mathrm{T}$-tests were performed to analyze the impact on the agreement between the BAC and the $\mathrm{BrAC}$, of whether the subject was passive/active for breath testing and performed a forced/non-forced expiration. A $p$-value of $\leq 0.05$ was chosen as the significant level. All statistical analyses were made using IBM SPSS Statistics version 19.

\section{Result}

\section{Patient and sample characteristics}

Of the 90 patients enrolled two patients were excluded, the first due to methanol poisoning, and the second as no approved breath test $\left(\mathrm{pCO}_{2}\right.$ over $\left.1.5 \mathrm{kPa}\right)$ was achieved. A total of 88 patients, 35 women $(40 \%)$ and 53 men (60\%), presented to the two EDs were included in the study. Table 1 presents the characteristics of the patients. The mean age of the patients was 45 years ( $S D \pm 19$, range $18-86)$. For 35 of the patients (51\%) the medical staff considered intoxication from alcohol or tablets to be the main reason for seeking medical care. Twenty-four (27\%) of the patients were found to have a BAC of $<0.04 \mathrm{mg} / \mathrm{g}$. The mean BAC for the whole population was $1.26 \mathrm{mg} / \mathrm{g}$, whereas the BAC for the alcohol positive patients ranged from 0.15 to $3.46 \mathrm{mg} / \mathrm{g}$, with a mean of $1.73 \mathrm{mg} / \mathrm{g}$. For the patients with a positive BAC $(n=64)$ the mean measured $\mathrm{BrAC}$ was $0.64 \mathrm{mg} / \mathrm{l}$ (range 0 to $1.71 \mathrm{mg} / \mathrm{l}$ ) and the mean $\mathrm{BrAC}_{\text {est }} 0.86 \mathrm{mg} / \mathrm{l}$ (range 0 to $2.03 \mathrm{mg} / \mathrm{l}$ ). This indicates a general upward adjustment of $34 \%$ of the $\mathrm{BrAC}_{\text {est }}$ as compared to the $\mathrm{BrAC}_{\text {meas }}$. There was also a clear difference in the calculated $\mathrm{BBR}$ with respect to use of the $\mathrm{BrAC}_{\text {meas }}$ and the $\mathrm{BrAC}_{\text {est }}$, see Table 1 for mean and range of the BBR to be compared with the assumption of a fixed conversion factor, e.g. 2100:1.

In total the 88 patients performed 201 breath tests. Of the first approved breath tests performed by each patient,

Table 1 Patient characteristics and characteristics of the first breath test performed and the blood and breath alcohol measures $(\mathbf{n}=\mathbf{8 8})$

\begin{tabular}{|c|c|c|c|c|}
\hline Data for all patients & $\mathbf{n}$ & Mean & SD & Range \\
\hline Gender: 53 men, 35 women & 88 & & & \\
\hline Age [years] & 88 & 45 & \pm 19 & $18-86$ \\
\hline$B A C[m g / g]$ & 88 & 1.26 & \pm 1.06 & $0.0-3.46$ \\
\hline $\mathrm{pCO} 2$, first approved breath test [kPa] & 88 & 3.54 & \pm 0.88 & $1.7-5.59$ \\
\hline No. of negative blood tests [n] & \multicolumn{4}{|c|}{$24(27 \%)$} \\
\hline No. of test with awake/sleeping subjects [n] & \multicolumn{4}{|c|}{ 63/15 (not all tests characterized) } \\
\hline No. of the forced/non-forced breath tests [n] & \multicolumn{4}{|c|}{ 10/57 (not all tests characterized) } \\
\hline Data for the patients with a positive BAC & $\mathbf{n}$ & Mean & SD & Range \\
\hline $\mathrm{BAC}[\mathrm{mg} / \mathrm{g}]$ & 64 & 1.73 & \pm 0.85 & $0.15-3.46$ \\
\hline Measured $\operatorname{BrAC}\left(\mathrm{BrAC}_{\text {meas }}\right)[\mathrm{mg} / \mathrm{l}]$ & 64 & 0.64 & \pm 0.36 & $0.0-1.71$ \\
\hline Estimated end-expiratory $\mathrm{BrAC}\left(\mathrm{BrAC}_{\mathrm{est}}\right)[\mathrm{mg} / \mathrm{l}]$ & 64 & 0.86 & \pm 0.43 & $0.0-2.03$ \\
\hline Ratio $B A C / B r A C_{\text {meas }}$ & 63 & 2994 & \pm 947 & $1758-7776$ \\
\hline Ratio BAC/BrAC est & 63 & 2144 & \pm 503 & $1130-3632$ \\
\hline
\end{tabular}


one breath test was found to be false positive with a measured $\mathrm{BrAC}>0.10 \mathrm{mg} / \mathrm{l}$ (the same applied for the patient's second breath test) and one breath test was found to be false negative (BAC $0.15 \mathrm{mg} / \mathrm{g}$ ) (sensitivity $98.4 \%$, specificity $95.8 \%)$.

\section{Relation between the BrAC and BAC}

In Figure 1a and b (see 1a) the correlation between the $\mathrm{BrAC}_{\text {meas }}$ and the $\mathrm{BAC}$ is presented. The regression equation $(y=0.368 x+0.0092 ; r=0.94)$ indicates that with an assumption of a BBR of 2100:1 (a ratio of 2:1 gives $y=0.5 x)$, the BAC would be underestimated with $26 \%$. If the $\mathrm{BrAC}_{\text {est }}$ was used to predict the $\mathrm{BAC}$, the underestimation was decreased to $6 \%(y=0.466 x+0.046, r=0.94)$ (Figure 1a and $\mathrm{b}$ (see 1b)). No significant offsets were found for the two measurement series, and the random errors expressed as the residual standard deviations were $0.0147 \mathrm{mg} / \mathrm{l}$ and $0.0182 \mathrm{mg} / \mathrm{l}$, respectively.

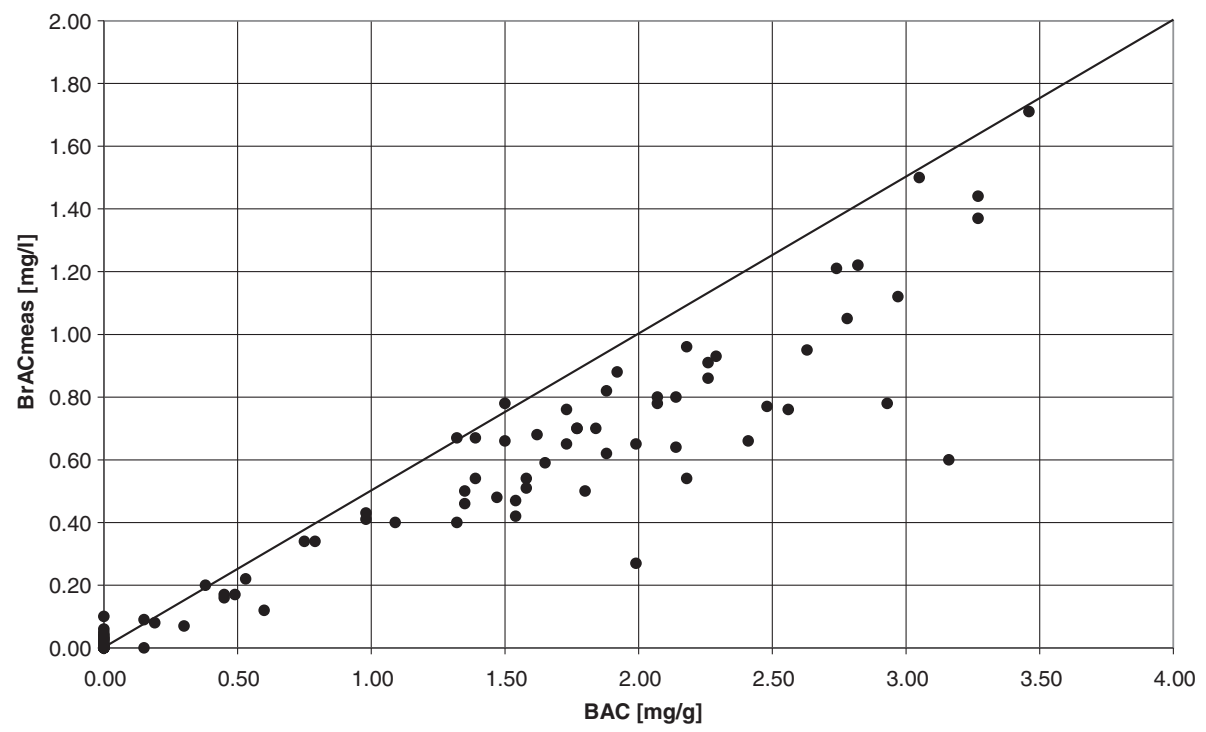

(a)

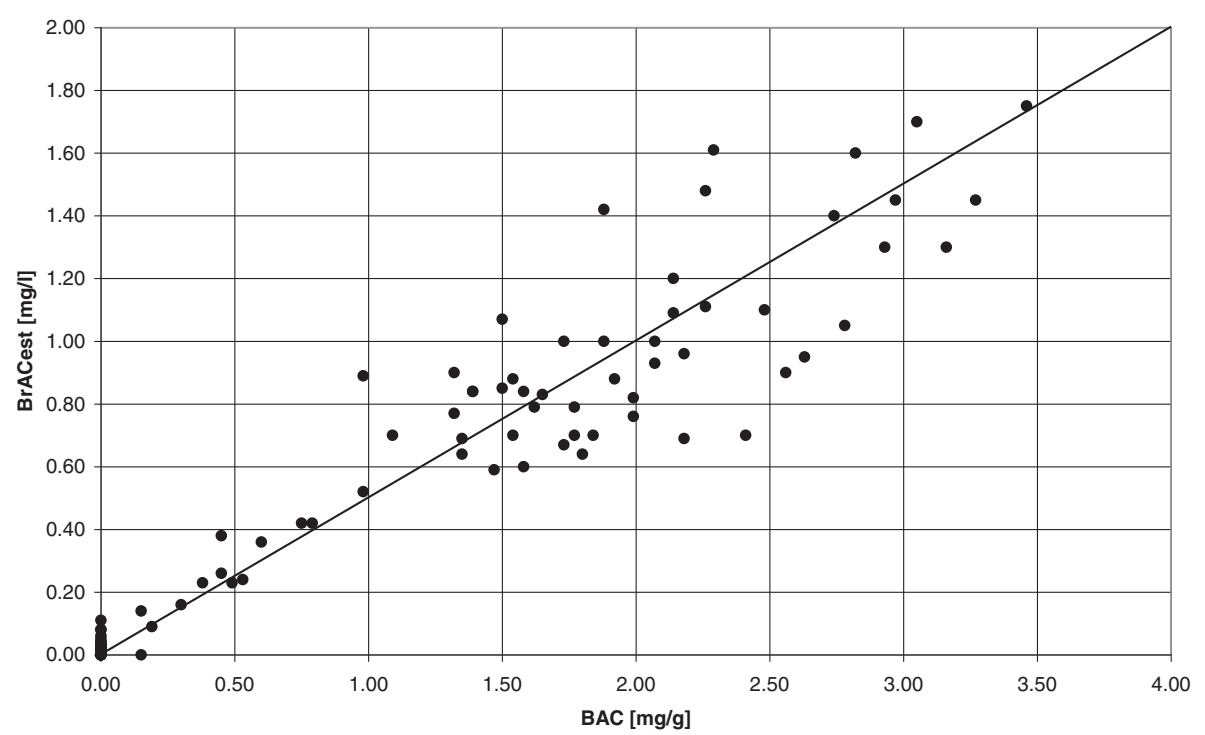

(b)

Figure 1 The correlation between the BAC and the BrAC, where the identity lines represents a BBR of 2100:1. (a) The $B r A C$ meas gave a clear underestimation of the $B A C$ with $26 \%(n=88 ; y=0.368 x+0.0092 ; r=0.94$. (b) Use of the $B r A C$ est resulted in an underestimation of the $B A C$ of only $6 \%,(n=88 ; y=0.466 x+0.0465 ; r=0.94)$, the reason for this is the reduced effect from difference in cooperation and duration of the expiration performed by the subjects. One clear example of this reduced effect is the two outliers visible in Figure 1a, which are moved into the population in Figure 1b. 


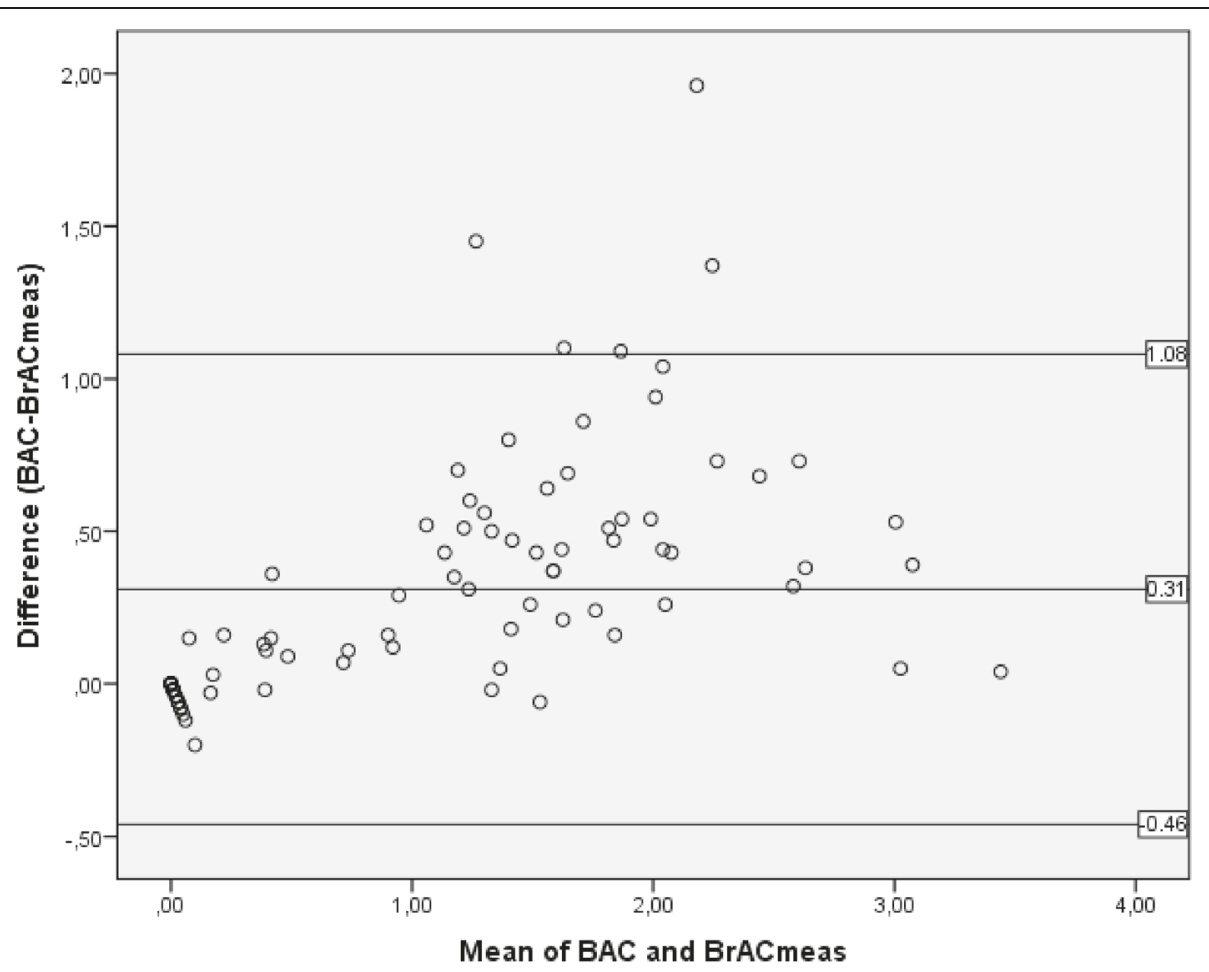

(a)

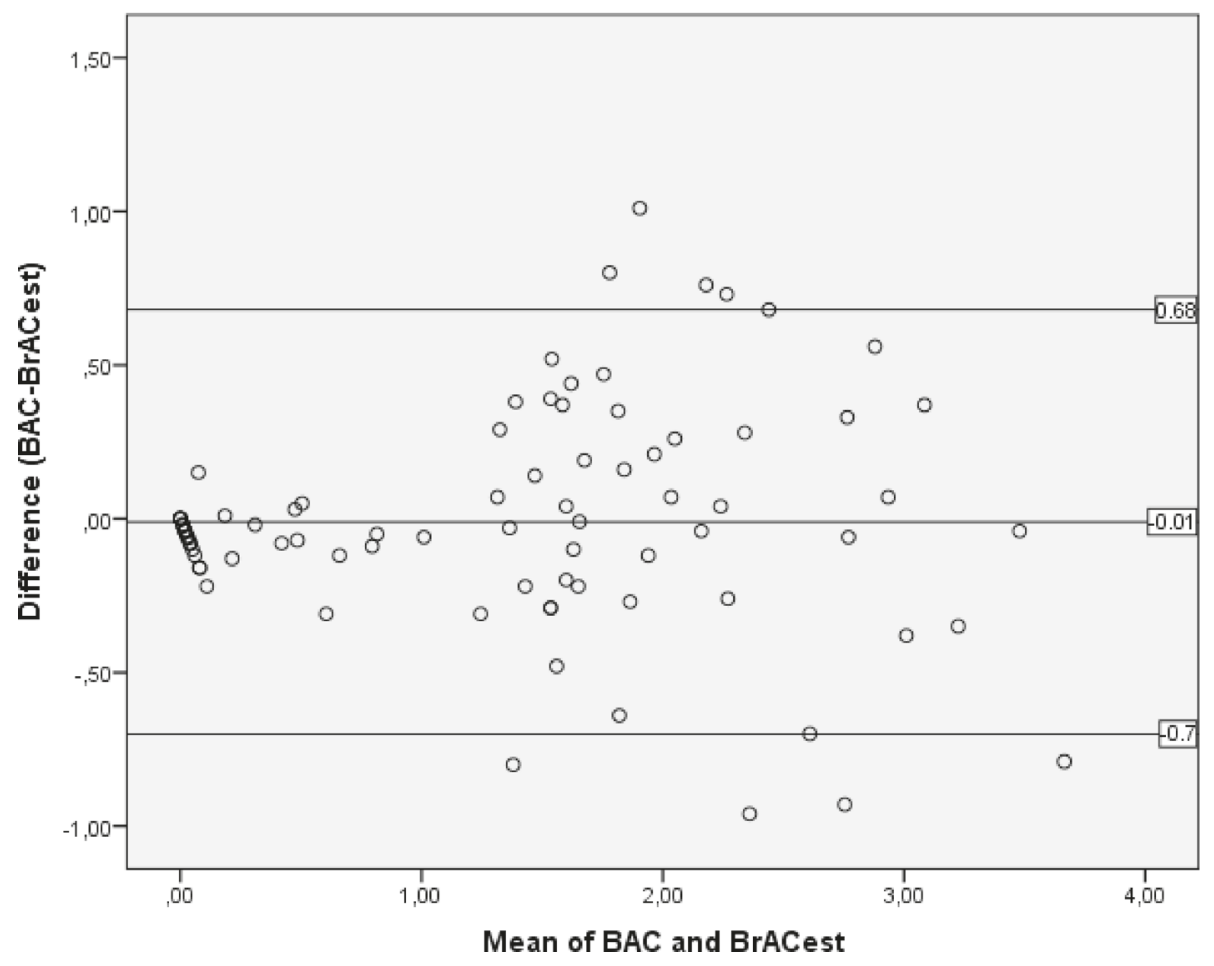

(b)

Figure 2 Analysis of the first breath sample $(n=88)$ illustrating the difference between the BAC and the BrAC with a Bland-Altman plot. (a) A mean bias of $0.31 \mathrm{mg} / \mathrm{g}$ was found between the BAC and the $B \mathrm{BrC}_{\text {meas }}$ upper limits of agreement (LOA) of $1.09 \mathrm{mg} / \mathrm{g}$ and lower LOA of $-0.46 \mathrm{mg} / \mathrm{g}$. (b) No bias was found between the BAC and the BrAC est, upper LOA of $0.68 \mathrm{mg} / \mathrm{g}$ and lower LOA of $-0.70 \mathrm{mg} / \mathrm{g}$. 
With a Bland Altman plot the agreement and differences between the BAC and the $\mathrm{BrAC}$ can be illustrated. Analysis of the difference between the BAC and the $\mathrm{BrAC}_{\text {meas }}$ showed a large positive bias $(0.31 \mathrm{mg} / \mathrm{g})$ (Figure 2a and b (see 2a)). Comparing the BAC and the $\mathrm{BrAC}_{\text {est }}$ showed no bias and a more even distribution (Figure 2a and $\mathrm{b}$ (see $2 \mathrm{~b})$ ). Including paired data for all approved breath tests $(n=201)$ only indicates a minor change of the mean bias presented in Figure $2 \mathrm{a}$ and $2 \mathrm{~b}$; from $0.31 \mathrm{mg} / \mathrm{g}$ to $0.28 \mathrm{mg} / \mathrm{g}$ (upper limits of agreement (LOA) $1.00 \mathrm{mg} / \mathrm{g}$ and lower LOA $-0.43 \mathrm{mg} / \mathrm{g}$ ), and from $0.00 \mathrm{mg} / \mathrm{g}$ to $-0.02 \mathrm{mg} / \mathrm{g}$ (upper LOA of $0.68 \mathrm{mg} / \mathrm{g}$ and a lower LOA of $-0.72 \mathrm{mg} / \mathrm{g}$ ), respectively.

\section{Difference in estimated BrAC between the two breath tests}

For evaluation of the repeatability of the presented value of the $\mathrm{BrAC}_{\text {est }}$ a Bland-Altman plot is presented in Figure 3. The data is from two sequential approved breath tests performed by 76 patients. The result indicated no bias, but the upper and lower LOA of $0.34 \mathrm{mg} / 2 \mathrm{l}$ and $-0.37 \mathrm{mg} / 2 \mathrm{l}$ (equal to $\mathrm{mg} / \mathrm{g}$ ) indicate that there was an evenly distributed difference in $\mathrm{BrAC}_{\text {est }}$ between the first and second breath test.

\section{The bias in relation to maximal measured level of $\mathrm{pCO}_{2}$}

The bias found between the $\mathrm{BAC}$ and the $\mathrm{BrAC}_{\text {meas }}$ can possibly be reflected in the length of the expiration, and thus the measured level of $\mathrm{pCO}_{2}$. For the first approved breath test $(\mathrm{n}=88)$ a mean $\mathrm{pCO}_{2}$ of $3.54 \mathrm{kPa}$ was found (range 1.66 - $5.59 \mathrm{kPa}$ ). Figure $4 \mathrm{a}$ and $\mathrm{b}$ (see $4 \mathrm{a}$ ) presents the bias between the $\mathrm{BAC}$ and the $\mathrm{BrAC}_{\text {meas }}$ in relation to the measured $\mathrm{pCO}_{2}$. For the breath tests with a measured $\mathrm{pCO}_{2}$ over $4.8 \mathrm{kPa}$ the value of the measured $\mathrm{BrAC}$ was used in Figure $4 \mathrm{a}$ and $\mathrm{b}$ (see $4 \mathrm{~b})$. Figure $4 \mathrm{a}$ and b (see 4b) illustrates a more even distribution around the $\mathrm{x}$-axis when the difference between the BAC and the $\mathrm{BrAC}_{\text {est }}$ is plotted in relation to the measured $\mathrm{pCO}_{2}$, which indicated less dependence on the $\mathrm{pCO}_{2}$, as compared to the results in Figure 4a and b (see 4a).

The influence from the patients' breath testing performance on the BrAC could also be assessed from the test characteristics documented in the study protocol. A forced or non-forced expiration was not found to have a significant effect $(p=0.09)$ on the bias between the BAC and the $\mathrm{BrAC}_{\text {est, }}$ whereas, the bias between the $\mathrm{BAC}$ and the $\mathrm{BrAC}_{\text {est }}$ for awake subjects was significantly $(\mathrm{p}=0.02)$ different from the bias for subjects who slept or had a lower level of consciousness (Table 2).

\section{Discussion}

During the study it was found that the personnel were able to attain approved breath tests from the patient's normal breathing without problem, after been given minimal user instructions from the test leader or from other enrolled and trained colleagues. The small gentle expiration needed for breath testing is of benefit for the many persons with respiratory impairment, such as

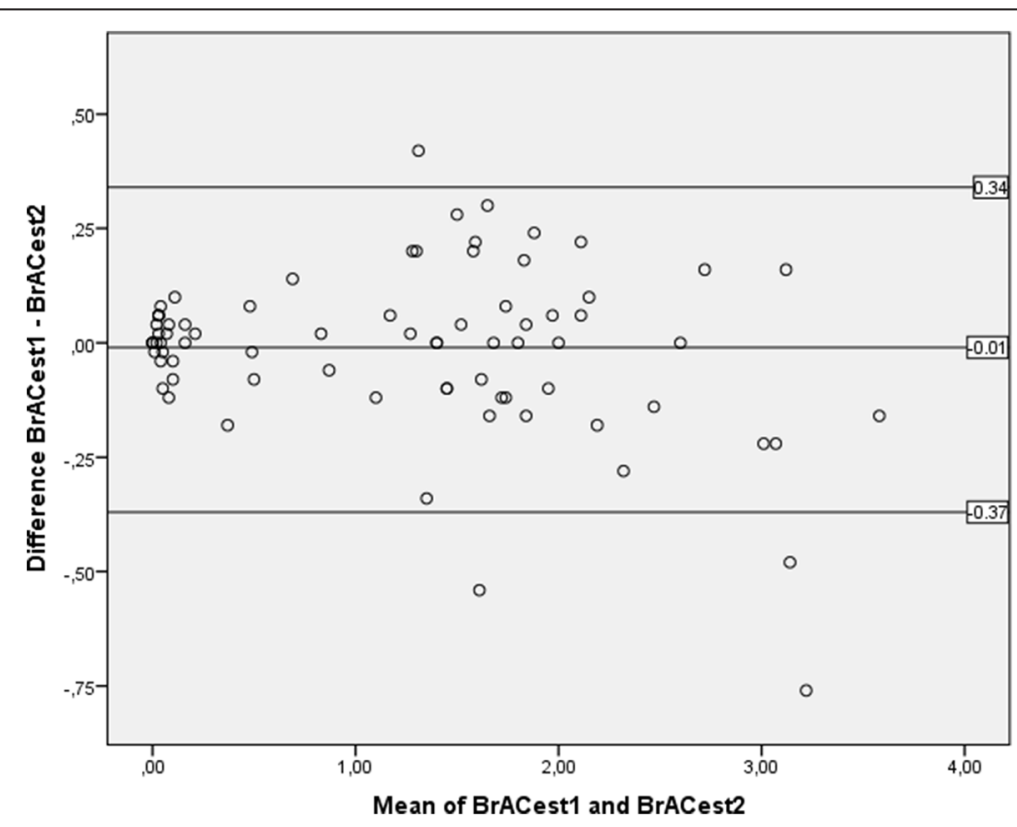

Figure 3 The Bland-Altman Plot presents the difference in estimated BrAC from two breath tests in relation to the mean of the estimated BrAC for the two breath tests $(\mathbf{n}=\mathbf{7 6})$. The plot indicates no bias and an even distribution of the upper and lower LOAs around 0 . The LOAs of $0.34 \mathrm{mg} / 2 \mathrm{I}$ and $-0.37 \mathrm{mg} / 2 \mathrm{I}$, indicate differences in the BrAC estimated from two sequential breath tests, and reflect the measurement repeatability. 


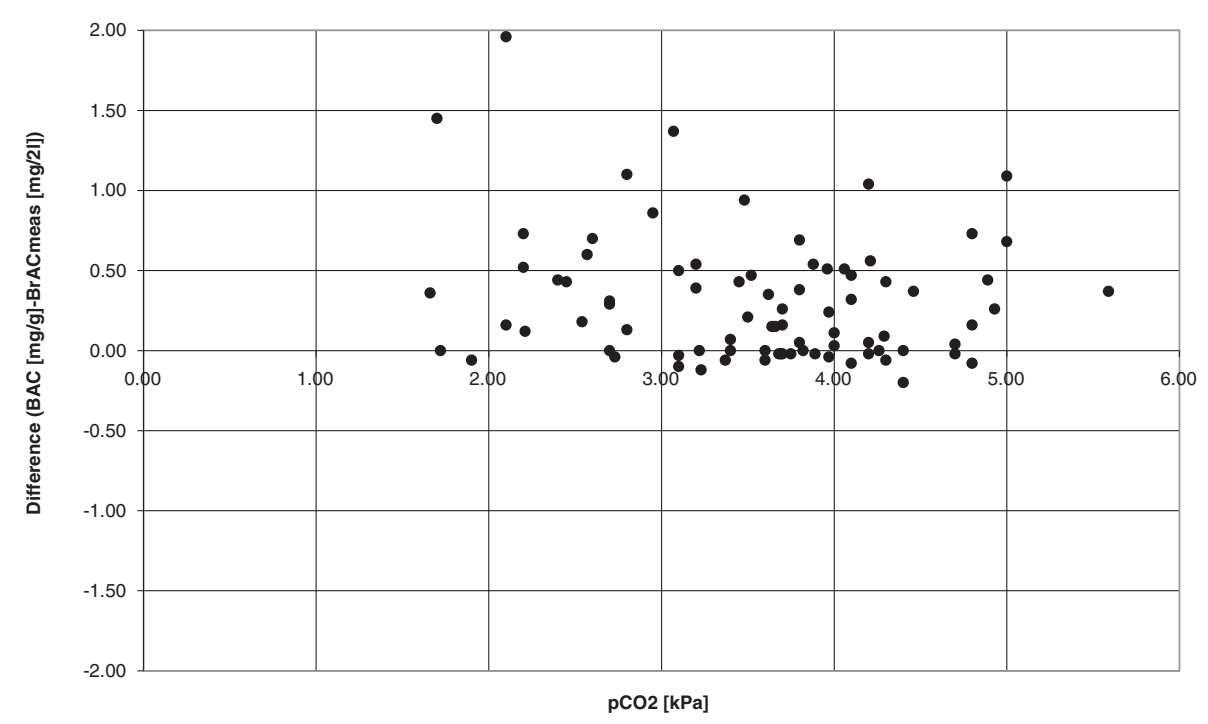

(a)

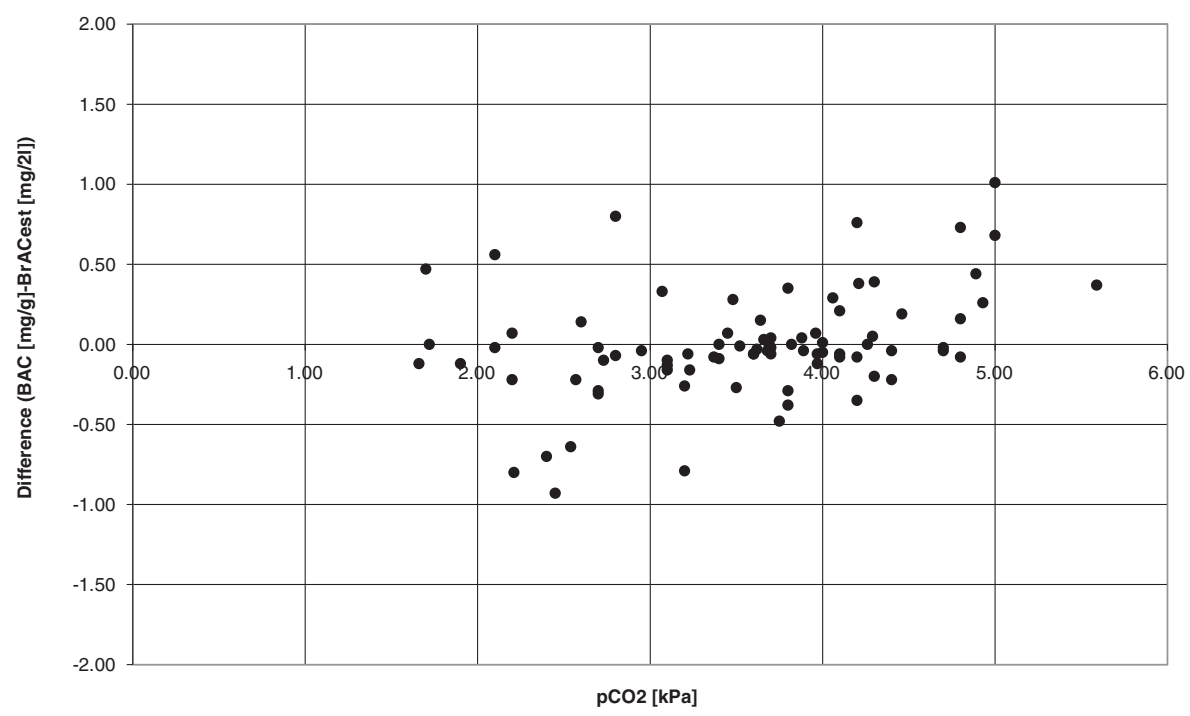

(b)

Figure 4 The bias between the $B A C$ and the $\mathrm{BrAC}$ in relation to the $\mathrm{pCO}_{2}$. (a) The underestimation of the $\mathrm{BrAC}$ meas as compared to the $\mathrm{BAC}$ is decreased with increased level of measured $\mathrm{pCO}_{2}$, which is achieved with increased length of expiration. (b) No bias and a more even distribution around the $x$-axis indicate a decreased influence from measured $\mathrm{pCO}_{2}$ with the use of $\mathrm{BrAC}_{\text {est }}$.

asthma and COPD, and variable consciousness who are seeking emergency care.

The results showed that with estimation of the BrAC with use of the expired $\mathrm{pCO}_{2}$ as a quality indicator $\left(\mathrm{BrAC}_{\mathrm{est}}\right)$, the influence of the patient's cooperation, passive/forced expirations, or length of expiration is reduced and the measurement accuracy increased. As compared to the reliability of the BrAC measured in the breath $\left(\mathrm{BrAC}_{\text {meas }}\right)$ which is clearly related to the level of the patient's cooperation and length of the expiration (Figures 1a and 2a). This is also illustrated in the more symmetric distribution in (Figure 4b, as compared to $4 \mathrm{a}$ ).

The results found in this study agree with previous results of ours, with an earlier prototype tested on emergency patients [15]. Another important result is that the variation in $\mathrm{BrAC}_{\text {est }}$ found between two sequential breath tests (Figure 3) corresponding to a BAC of $0.3 \mathrm{mg} / \mathrm{g}$, is of no clinical significance since a variation of that level would not make any difference in the medical assessment or care of the patient. 
Table 2 The influence of breath test performance in relation to the mean bias of the BAC and the estimated BrAC (BrAC $\left.C_{\text {est }}\right)$

\begin{tabular}{lllll}
\hline & $\begin{array}{l}\text { N } \\
\end{array}$ & $\begin{array}{l}\text { Mean bias between } \\
\text { the BAC and the } \\
\text { BrAC }_{\text {est }}\end{array}$ & $\begin{array}{l}\text { Standard } \\
\text { deviation }\end{array}$ & P-value \\
\hline Forced expiration & 10 & -0.15 & 0.39 & \\
$\begin{array}{l}\text { Non-forced expiration } \\
57\end{array}$ & 0.05 & 0.32 & 0.09 \\
Awake & 63 & -0.03 & 0.34 & \\
$\begin{array}{l}\text { Sleeping or lowered } \\
\text { level of consciousness }\end{array}$ & 15 & 0.20 & 0.37 & 0.02 \\
\hline
\end{tabular}

A p-value $<0.05$ was considered significant.

Since the BBR depends on many different factors, there is significant controversy regarding the assumption of a fixed BBR in converting between BrAC and BAC. Despite our knowledge of this, a BBR of 2100:1 was used for comparison in Figure 1 and the Bland Altman plots in Figure 2. The actual BBR for a paired data set of a $\mathrm{BAC}$ and BrAC is dependent on, for example whether the subject is in the absorption or the elimination phase of alcohol [20], the length of the expiration [10], the attained alcohol concentration [21,22], eventual time elapsed between measurement of the two specimens $[8,23]$, and whether arterial or venous blood are sampled [20]. Concerning the set-up of this study only venous blood samples were analyzed and the recommended maximum time of 30 minutes between the blood test and the breath tests was not exceeded for any of the patients. However, the time elapsed since the patient consumed alcohol was unknown and therefore whether the patient was in the absorption or elimination phase. The effect on the level, and the variability, in BBR as a result of different lengths of expiration can be seen in the BBR calculated for the $\mathrm{BrAC}_{\text {meas }}$ as compared to the $\mathrm{BrAC}_{\text {est }}$. With the $\mathrm{BrAC}_{\text {est }}$, which uses the $\mathrm{CO}_{2}$ as a tracer gas in order to reduce the influences from variation in type and duration of the expiration, the mean BBR was significantly reduced (from 2994 to 2144) and the standard deviation of the mean was reduced to half (from 900 to 500).

In addition the patients enrolled in the study showed a large difference in levels of intoxication. In both Figures 1 and 2 it is shown that at BAC below $1 \mathrm{mg} / \mathrm{g}$ the distribution is small, whereas it is increased, up to 4 times, at $\mathrm{BAC}$ over $1 \mathrm{mg} / \mathrm{g}$. This increase in variability of the $\mathrm{BrAC}$ at higher level of BAC could be the result of increased variability in the BBR, which in turn could be related to increased effect from the intoxication level, and if the patient sought emergency care in the absorption or elimination phase of alcohol for which the distribution of alcohol between venous blood and breath are different.

A tendency of increased variability in BBR at increased concentrations has also been found by Sebbane et al.
[24]. Sebbane et al. found a BBR of $2615 \pm 387$ when breath testing ED patients, and concluded that the legal conversion factor of 2000:1 used in France was not appropriate in the ED setting. In Sweden, a BBR of 2100:1 is used in breathalyzers for legal purposes [8]. As compared to 2000:1 and 2100:1, the higher BBR found by Sebbane et al. and for $\mathrm{BrAC}_{\text {meas }}$ in this study can possibly be explained by the lower grade of cooperation and lower expired volume for patients as compared to healthy subjects, i.e. drunk drivers. However, the results of our study indicate that with use of $\mathrm{BrAC}_{\text {est }}$ the BBR used for legal purposes in the US and in Sweden (2100:1) is most appropriate for medical applications.

The method of estimating the $\mathrm{BrAC}$ with the assumption that the end-expiratory $\mathrm{pCO}_{2}$ is $4.8 \mathrm{kPa}$ has been investigated with both healthy subjects and patients with respiratory impairments [14]. When breath testing patients this can introduce inaccuracies, e.g. for patients with respiratory diseases or respiratory distress the $\mathrm{BrAC}_{\text {est }}$ might be less accurate. In Figures $1 \mathrm{~b}$ and $2 \mathrm{~b}$ it is shown that the $\mathrm{BrAC}_{\text {est }}$ gives a better agreement to a BBR of 2100:1 and an even but somehow increased distribution, as compared to the $\mathrm{BrAC}_{\text {meas }}$, see Figures $1 \mathrm{a}$ and $2 \mathrm{a}$. This increase in variability can indicate that the assumption of a fixed value $\mathrm{pCO}_{2}$ value of 4.8 $\mathrm{kPa}$ is less appropriate for emergency patients. However, this effect has to be compared to the underestimation of $\mathrm{BAC}$ of $26 \%$ seen with the $\mathrm{BrAC}_{\text {meas }}$. Another indication are found in two outliers in $\mathrm{BrAC}_{\text {est }}$ for breath tests $(n=201)$ performed on a patient admitted with respiratory distress $\left(\mathrm{n}=2, \mathrm{pCO}_{2}=1.6 \mathrm{kPa}\right.$ and $2.0 \mathrm{kPa}$, respectively). An additional indication of the inaccuracy that the measurement method introduces by assuming a constant endexpiratory $\mathrm{pCO}_{2}$ for all patients is found in Table 2. This shows a significant difference in the mean bias between the $\mathrm{BAC}$ and the $\mathrm{BrAC}_{\text {est }}$, for the breath tests performed on awake patients and those performed on sleeping patients or on patients with a lower level of consciousness.

A problem with the breathalyzer tested which was highlighted during the study was its inability to distinguish between ethanol and methanol in the breath. As compared to breath testing drivers, the sensitivity for methanol is a larger problem in the medical application, since fast and accurate assessment of methanol poisoning is needed because the medical treatment of these patients are completely different to the treatment of ethanol intoxication. However, the IR technology can enable high selectivity [13]. If modified with a second adjacent wavelength for detection of ethanol, selectivity between ethanol and methanol in the breath would be possible with the breathalyzer prototype tested.

Frequent and early objective breath alcohol screening in emergency care could lead to avoidance of differential diagnosis errors, decreased risk of patients being 
discriminated against or incorrectly treated [5], and decreased costs through decreased use of certain invasive diagnostic procedures [25]. However, state-of-the-art devices available on EDs today have limitations considering usefulness and reliability. This study indicates an innovative solution to these problems. With use of the expired $\mathrm{pCO}_{2}$ as a quality marker the breath alcohol concentration can be reliably assessed in emergency care patients regardless of their cooperation.

\section{Future research}

The documented sensitivity of $98.4 \%$ and specificity of 95.8\% are considered acceptable for this breathalyzer prototype. However, significant technical improvements have been implemented in the next generation, and that within decreased dimensions. The latest technology provides opportunities for continued research of the application in regular clinical use. Areas of particular interests are diagnostic efficiency and the impact on healthcare economics. Additionally, more research is required to investigate the practical usability of this kind of handheld breathalyzer to make it as user-friendly as possible in the ED context.

\section{Competing interests}

The authors declare that they have no competing interests.

\section{Authors' contributions}

AKA, $\mathrm{BH}$ conceived the study and obtained the research funding, and together with $\AA \mathrm{MA}$ and $\mathrm{MC}$ they designed the study. AKA, JK, and LW took active part in the collection of data, and supervised the personnel at the emergency departments. AKA and JK performed the data analysis. AKA and JK drafted the manuscript, and all authors contributed substantially to its revision. AKA and ÅMA takes responsibility for the paper as a whole, ÅMA is corresponding author. All authors read and approved the final manuscript.

\section{Acknowledgment}

We are very thankful to the personnel involved, at the ED at Uppsala University Hospital and the ED at Södersjukhuset, for their engagement and help with performing this study. A special thanks to Ellinor Berglund, research coordinator at the ED of Södersjukhuset.

\section{Author details \\ ${ }^{1} H$ ök Instrument AB, Västerås, Sweden. ${ }^{2}$ Karolinska Institutet, Department of Clinical Research and Education, Södersjukhuset, Stockholm, Sweden. ${ }^{3}$ Section of Emergency Medicine, Södersjukhuset, Stockholm, Sweden. ${ }^{4}$ Department of Medical Sciences, Uppsala University, Uppsala, Sweden. ${ }^{5}$ School of Nursing, University of Adelaide, Adelaide, Australia. ${ }^{6}$ Department of Emergency Care, Uppsala University Hospital, Uppsala, Sweden. ${ }^{7}$ Department of Public Health and Caring Sciences, Uppsala University, Uppsala, Sweden. ${ }^{8}$ Department of Surgical Science, Anesthesiology and Intensive Care, Uppsala University, Uppsala, Sweden.}

Received: 15 October 2014 Accepted: 21 December 2014

Published online: 06 February 2015

\section{References}

1. Brismar B, Engström A, Rydberg U. Head injury and intoxication: A diagnostic and therapeutic dilemma. Acta Chir Scand. 1983;149:11-4.

2. Efskind Harr M, Heskestad B, Ingebrigtsen T, Romner B, Rønning P, Helseth E. Alcohol consumption, blood alcohol concentration level and guideline compliance in hospital referred patients with minimal, mild and moderate head injuries. Scand J Trauma Resusc Emerg Med. 2011;19:25.
3. Rücker G, Eiser T. Alkoholbestimmung im rettungsdienst. Notfall Rettungsmedizin. 2001;4:39-45.

4. Cherpitel C, Bond J, Ye Y, Room R, Poznyak V, Rehm J, et al. Clinical assessment compared with breathalyzer reading in emergency room: concordance of ICD-10 Y90 and Y91 codes. Emerg Med J. 2005;22:689-95.

5. Gentilello L, Villaveces A, Ries R, Nason KS, Daranciang E, Donovan DM, et al. Detection of acute alcohol intoxication and chronic alcohol dependence by trauma staff. J Trauma Injury Infect Crit Care. 1999;47:1131-9.

6. Gibb K, Yee A, Johnston C, Martin SD, Nowak RM. Accuracy and usefulness of a breath alcohol analyzer. Ann Emerg Med. 1984;13:516-20.

7. Vonghia L, Leggio L, Ferrulli A, Bertini M, Gasbarrini G, Addolorato G, et al. Acute alcohol intoxication. Eur J Int Med. 2008;19:361-7.

8. Jones AW, Andersson L. Variability of the blood/breath alcohol ratio in drinking drivers. J For Sci. 1996;41:916-21.

9. Jones AW, Andersson L. Comparison of ethanol concentration in venous blood and end-expiratory breath during a controlled drinking study. Forensic Sci Int. 2003;132:18-25.

10. Hlastala MP, Anderson JC. The impact of breathing pattern and lung size on the alcohol breath test. Ann Biomed Eng. 2007;35:264-72.

11. Hök B, Pettersson H, Kaisdotter Andersson A, HaasI S, Member, IEEE, Åkerlund P. Breath analyzers for alcolock and screening devices. IEEE Sensors J. 2010;10:10-5.

12. Fransson M, Jones AW, Andersson L. Laboratory evaluation of a new evidential breath-alcohol analyser designed for mobile testing - the Evidenzer. Med Sci Law. 2005;45:61-70.

13. Harding P. Methods for Breath Analysis. In: Garriott JC, editor. Medical-Legal Aspects of Alcohol. 4th ed. Tucson: Lawyers \& Judges Publishing Company, Inc; 2003. chapter 8.

14. Jonsson A, Hök B, Andersson L, Hedenstierna G. Methodology investigation of expirograms for enabling contact free breath alcohol analysis. J Breath Res. 2009:3:036002

15. Kaisdotter Andersson A, Hök B, Rentsch D, Ruecker G, Ekström M. Improved breath alcohol analysis in patients with depressed consciousness. MBEC. 2010;48:1099-105.

16. Kaisdotter Andersson A, Hök B, Ekström M. Influences from breathing pattern on alcohol and tracer gas expirograms - implications for alcolock use. For Sci Int. 2011:206:52-7.

17. Lumb AB. Carbon Dioxide. In: Nunn's Applied Respiratory Physiology Chapter 10, 6th. Philadelphia: Elsevier/Butterworth Heinemann; 2005.

18. Jones AW. Hospital alcohol test not completely easy to use for legal purposes. Conversion of ethanol levels in plasma or serum to permillage level in blood. Lakartidningen. 2008;105(6):367-8.

19. Bland JM, Altman DG. Statistical methods for assessing agreement between two methods of clinical measurement. Lancet. 1986;1:307-10.

20. Jones AW, Norberg $\AA$, Hahn RG. Concentration-time profiles of ethanol in arterial and venous blood and end-expired breath during and after intravenous infusion. J Forensic Sci. 1997;42:1088-94.

21. Haffner HT, Graw M, Dettling A, Schmitt G, Schuff A. Concentration dependency of the BAC/BrAC (blood alcohol concentration/breath alcohol concentration) conversion factor during the linear elimination phase. Int J Legal Med. 2003;117:276-81.

22. Pavlic M, Grubwieser P, Brandstätter A, Libiseller K, Rabl W. A study concerning the blood/breath alcohol conversion factor Q: Concentration dependency and its applicability in daily routine. Forensic Sci Int. 2006:158:149-56.

23. Currier G, Trenton A, Walsh P. Relative accuracy of breath and serum alcohol reading in the psychiatric emergency service. Psychiatr Serv. 2006;57:34-6.

24. Sebbane M, Claret P-G, Jreige R, Dumont R, Lefebvre S, Rubenovitch J, et al. Breath analyser screening of emergency department patients suspected of alcohol intoxication. J Emerg Med. 2012;43:747-53.

25. Jurkovich G, Rivara F, Gurney J, Seguine D, Fligner CL, Copass M. Effects of alcohol intoxication on the initial assessment of trauma patients. Ann Emerg Med. 1992;21:704-8. 